\title{
Meteorological Indigenous Knowledge Systems for Prediction of Rainfall in the Chimanimani District of Zimbabwe and Potential for Community Disaster Preparedness
}

\author{
Pindai M. Sithole' ${ }^{1}$ Moses Chundu ${ }^{2}$ \\ ${ }^{1}$ Academic Department, Africa Leadership and Management Academy (ALMA), Harare, Zimbabwe \\ ${ }^{2}$ Faculty of Business Management Sciences and Economics, University of Zimbabwe, Harare, Zimbabwe \\ Email: sitholepindai@gmail.com,mtgjcc@gmail.com
}

How to cite this paper: Sithole, P. M., \& Chundu, M. (2020). Meteorological Indigenous Knowledge Systems for Prediction of Rainfall in the Chimanimani District of Zimbabwe and Potential for Community Disaster Preparedness. Open Journal of Social Sciences, 8, 35-45. https://doi.org/10.4236/jss.2020.810004

Received: August 24, 2020

Accepted: October 7, 2020

Published: October 10, 2020

Copyright ( 2020 by author(s) and Scientific Research Publishing Inc. This work is licensed under the Creative Commons Attribution International License (CC BY 4.0).

http://creativecommons.org/licenses/by/4.0/ (c) (i) Open Access

\begin{abstract}
The paper focuses on indigenous knowledge systems (IKS) which people of Chimanimani District of Zimbabwe use to predict rainfall patterns. This is based on a 2019 socio-ecological study conducted in the district. The main objective of the study was to establish the extent of use and efficacy of meteorological IKS for prediction of rainfall in Chimanimani and to explore potential contribution of the meteorological IKS in local community disaster preparedness. The study came at the backdrop of a trail of unprecedented human and environmental destruction that occurred in the district following the devastating Cyclone Idai of April of 2019. Despite the existence of IKS and modern weather forecasting tools, the Cyclone seemed to have caught both the community and government unprepared, prompting this study. In depth-interviews and storytelling were conducted with traditional leaders and community elders. A qualitative approach was applied through the use of detailed interviews and focus group discussion to collect meteorological IKS from three communities in the district. Thematic analysis anchored in the interpretive and ontological paradigms was utilized within the realism theory. The meteorological IKS found in the study were classified into five interpretive categories namely vegetation, animals, birds, insects and cosmology. The study concluded that meteorological IKS are no longer widely used due to a number of factors including inferioritisation and limited documentation. It was noted that the IKS have potential for incorporation into the community disaster preparedness frameworks.
\end{abstract}

\section{Keywords}

Indigenous Knowledge Systems, Weather Prediction, Disaster Preparedness, 
Meteorology, Cyclone

\section{Introduction}

In April of 2019, Zimbabwe was hit by a devastating Cyclone Idai $^{1}$ which affected Chimanimani District of Zimbabwe and the neighbouring district of Chipinge. The extent of damage was exaggerated by the fact that the community seemed to have been caught completely off guard. Similarly, the way the government responded through the national Civil Protection Unit (CPU) was insufficiently effective compared to the way the rest of the affected region responded. The views of experts and the general public were that the community and government should have been more alert to minimize human casualties from the cyclone.

This raises a question as to whether the national meteorological unit was not equipped to detect early warnings of the cyclone on time to invoke mitigation measures. Did the local indigenous meteorological systems equally fail to put the communities on alert? This necessitated the current study whose motivation was twofold: Firstly, to explore meteorological indigenous knowledge systems in Chimanimani District to determine if they could have a space in the conventional meteorology system in Zimbabwe to help predict rainfall for enhanced productivity. Secondly, the study sought to determine the extent to which the local knowledge established could be used towards disaster preparedness with a view to minimising human loss, material and destruction of environment caused by adverse weather conditions.

Thus, the discussion in the paper joins others on the need to embrace knowledge beyond the confines of the Western knowledge systems which may not fit some peculiarities of communities in Africa like Chimanimani District. In other words, the discussion is a confluence of three theories. The theories are realism, decoloniality and knowledge-plurality and these have been argued extensively elsewhere (Guzzini, 2017; Matos-Ala, 2018; Ndlovu-Gatshen, 2015). Realism is discussed in Section 3 of this paper as an underpinning theoretical discourse for this paper, while the other two are briefly discussed here. Decoloniality refers to post-colonial policy and/or legislative efforts by governments to untangle a primarily Eurocentric worldview or world order across all facets of life. As for knowledge plurality, this is a theory which states that the production of knowledge should not remain a long-standing perceived universality of it as selfishly located in the Western epistemology and culture. As can be seen, knowledge plurality is actually an element of decoloniality theory but one can choose to use it as a separate theory on its own. Together, these theories are seen as necessary ${ }^{1}$ An intense tropical cyclone which caused catastrophic damage in Chimanimani and Chipinge Districts of Zimbabwe as well as some parts of Mozambique and Malawi. It claimed more than 1300 people dead and many more missing. Property, roads, bridges and the general environment worth hundreds of millions of dollars were destroyed beyond repair. 
theoretical foregrounding for transformative and sustainable development in the once socio-culturally marginalised countries of the southern hemisphere.

As will be seen later, the paper reveals that Chimanimani District has its own indigenous knowledge systems for predication of weather which, in itself, is a dimension of knowledge plurality. However, the tragedy is the increasingly loss of the knowledge and its application through generations in Chimanimani and similar communities. This is because indigenous knowledge systems in most communities in the southern hemisphere are "diluted" or "overshadowed" by Western epistemologies preached and enforced during colonial and even in today's post-colonial era (Logan, 2008; Mapara, 2009; Sithole, 2020). In other words, most formerly colonised nations face the same fate of devaluation and marginalisation of their social and cultural resources. In some instances, dehumanisation of the colonies' own indigenous knowledge systems became part of the major colonial practice as evidenced in their deliberate exclusion from the education systems (Muchena, 1990; Shizha, 2013). This situation was borne out of the Western dominant-superiority attitude which largely accounted for imposition of their own knowledge systems to the local citizens (Logan, 2008). Almost without exception, the imposition was made through the implementation of Western based education systems in the colonies with today's resultant effect of westernisation of knowledge and development (Mapara, 2009; Matos-Ala, 2018). Essentially, the paper brings to the fore the little known meteorological indigenous knowledge systems with a focus on three communities of Chimanimani District. Underpinned by the knowledge decolonisation trajectory, the study results will seek to influence national policies towards knowledge-plurality in rainfall prediction and disaster preparedness.

The overall aim of the study was to explore meteorological indigenous knowledge systems in Chimanimani District for prediction of rainfall. That is on one hand, to investigate the categories and descriptions of the meteorological IKS in the district communities studied. On the other hand, to explore the possibility of pluralism of Western and African knowledge systems in the rainfall predication trajectory. Accordingly, the specific objectives which guided the study were to:

- Identify indigenous knowledge systems that relate to rainfall predication in Chimanimani District;

- Assess the prevalence use of indigenous knowledge systems for prediction of rainfall in Chimanimani District;

- Establish if the meteorological IKS is known by community members aged between 30 and 60; and

- Explore potential contribution of the weather meteorological indigenous knowledge systems in local community disaster preparedness.

\section{Theoretical Underpinning: Realism Theory}

Generally, the Realism Theory refers to imperative of understanding reality of a situation or phenomenon within its own contextual disposition (Battiste, 
2005; Rosch \& Lebow, 2018; Stefanelli et al., 2017). The theory was chosen for this paper to provide a contextual and localised analysis, and discussion and interpretation of the meteorological IKS in the studied communities of Chimanimani District. The application of realism theory for contextual understanding of socio-economic development and meteorology in particular in today's reality of climate change is gaining prominence in Africa and elsewhere. The realistic view and application of meteorological IKS have been incorporated in the ecological disaster early warnings strategies of some of the local authorities in Kenya (Liang, 2017), desertification and range ecology framework in Morocco (Davis, 2004), agricultural systems in northern Malawi (Moyo, 2010), policy advocacy for inclusion of IKS in meteorological sciences curricula in South Africa (Riffel, 2015) and linkages of conventional and IKS in weather forecasting in Zaka District of Zimbabwe (Makwara, 2013). The realization that IKS is central in meteorology and climatology has been aptly expressed by Mahony and Caglioti (2017) who retorts that “... new scholarship is showing more directly how the conduct of meteorology and climatology is deeply entangled with society [local community knowledge systems]" (Mahony \& Caglioti, 2017).

Historically, realism evolved from idealism theory following World War II where world leaders at that time believed that it was possible for the world to have a homogenous framework in order to promote and maintain peace among nations (Guzzini, 2017). This idealist theory was fundamentally flawed as it ignored the unique differences of nations with regard to their socio-geographical perspectives, cultural underpinnings, economic differentials and stages of development. Furthermore, the human nature of ever-in-pursuit of power and control over others were unfortunately overlooked in the drive for the idealist theory. So, early in the $20^{\text {th }}$ century, it dawned on the world leaders that peace building, rationality on exercising power and control in the intra and interstate are paradigms that require contextualized ontological lenses. The ontology discourse, in this case, refers to both a philosophy and practice to consider unique realities of states and communities to promote and accelerate progressive development in the various domains of national aspirations including politics. Thus, realism theory has become an acceptable theoretical framework for development analysis largely in international relations or foreign policy domains (Guzzini, 2017) and, to a less extent, in the education sector (Boeren, 2019; Shava \& Heystek, 2019).

It is noted, at least in the literature reviewed, that realism theory has not been explored and applied in the analysis, understanding and documentation of meteorological IKS in communities. Thus, realism theory has been used in this paper as an attempt to advance the already ongoing postulations that indigenous knowledge systems are socio-cultural, geographically rooted, evolving and ontologically juxtaposed (Fonda, 2011; Kaya \& Seleti, 2013; Matos-Ala, 2018; Muyambo \& Maposa, 2014; Rim-Rukeh, Irerhievwie, \& AgbozuI., 2015, Sithole, 2020). The decision for application of realism theory in this paper lies in the fact that reality in the Chimanimani District may not be universally applied in other 
communities in Zimbabwe or the world at large. This is because of the relativistic nature of indigenous knowledge systems (Aniah, Aasoglenang, \& Bonye, 2014). However, whilst the actual indigenous knowledge systems may not be applicable to other communities, the idea of their effectiveness can be applied.

\section{Methodology}

The methodology employed in the study was anchored on the humanistic philosophy (Creswell, 2014; Ragab \& Arisha, 2017) which was informed by the fact that the subject matter studied is socio-ecologically constructed, reality explored is a lived experience of the people bounded in a specific context of the Chimanimani District. Given the uniqueness of the physical and socio-cultural context in which the meteorological IKS reality occurs in the studied communities, the findings were not to be generalized but can be extrapolated to other communities with similar characteristics. Data were collected through interviews and focus group discussions conducted with the selected community members and traditional leadership as well as non-participant observations of the surroundings. The use of different sources of data was necessary because of the characteristic of qualitative phenomena to possibly exist in multiple realities. Data were collected from the natural sites (communities) where the participants use the meteorological IKS to forecast weather. This also put the study participants at ease to share the information with the researchers when they were physically in their communities.

Of the total 27 interviewees, 17 (64\%) were male and 10 (36\%) were female. Snowball sampling was applied for the selection of the interviewees because it was crucial to interview individuals who were recommended by others as possessing sound knowledge on meteorological IKS. The choice for traditional leaders and community elders and the particular age group chosen (60 to 90 years) was informed by the fact that they are generally viewed as knowledge reservoirs of indigenous knowledge, community history, community beliefs and normative practices (Aniah et al., 2014; Fonda, 2011; Prussin, 2007).

One of the authors of this paper shares the same culture and language of the communities studied. This facilitated greatly in terms of community entry social protocols, community rapport, sampling, data collection process, translation of views expressed in the local Ndau language into English and the interpretation of the findings gathered. In fact, the authors together with two research assistants (one male and one female) from the communities studied, collected the data required for the study. The research assistants were taken through an intensive half-day orientation to the research and training on the data collection tools. This was followed by another half-day the following day of pilot-testing in one of the Wards in the district which was not part of the sampling frame but had similar characteristics. The decision for inclusion of local people as research assistants was crucial in the study to enhance acceptability and to address language problem for most of the study participants could not speak English. To ensure quality of the data. The direct interaction with participants in their respective 
communities provided valuable insights into the subject matter studied.

The first stage of data collection involved detailed in-depth interviews with 27 people who comprised 12 traditional leaders and 15 community elders aged between 60 and 90 years in three communities (municipal wards) in the district. The communities enumerated were Wards 15 (around the town centre), 18 (Biriri area) and 21 (Rusitu area). It should be noted that Ward 18 is geologically located in the dry area of the district while the other two are in zones which usually receive between normal to high rainfall annually. Although the other 20 Wards in the district were not studied, Ward 15 represented social differentiating factors that could be possibly found in every Ward and this is so given the close proximity of the Wards in the district and the semi-cosmopolitan characteristic of the town. It is worth mentioning that all the study participants shared a common socio-cultural history and practice as well as native language called Ndau. It is important to point out these characteristics since Indigenous knowledge systems are firmly rooted in people's social norms, culture, history, language and native environment (Shizha, 2013).

The second stage of the data collection involved establishment of credibility of views gathered from the interviews. This was done through three focus group discussions held with one group of traditional leaders and with two community elders that comprised 7 people in each group also aged between 60 and 90 . Through use of snowball sampling, the total 21 participants of the three focus group discussions were selected from the same municipal wards where the interviewees were selected but they were different individuals. This was crucial to achieve an objective and independent validation of the meteorological IKS obtained and the explanations given about rainfall prediction. In other words, this was a member check strategy employed in the study to determine truth or trustworthiness of meteorological IKS findings in the district and this resonates with Birt, Scott, Cavers, Campbell, \& Walter (2016) and Harper \& Cole (2012).

Thematic analysis, guided by an inductive approach, was used to analyse the data sets obtained from interviews, focus group discussions and observations. In addition, an interplay of interpretative and ontological paradigms were utilised to achieve contextual interpretations of the meteorological IKS collected. On the aspect to determine if the meteorological IKS were known by all generations in the communities studied, 19 people (11 male and 8 female) aged between 30 and 60 were randomly selected to answer one question. That is, they were asked if they knew any indigenous knowledge systems for prediction of rainfall in their respective communities of Chimanimani District. If anyone responded affirmatively, a follow up question required the person to state and describe the meteorological IKS familiar to the individual.

All the study participants were indexed for unique identification when one's data is referenced in the presentation and discussion of the findings. Thus, traditional leaders were indexed TL01 up to TL12, community elders, CE01 up to CE15 and study participants below the age of 60, YA01 up to YA19. 


\section{Presentation of Results}

The meteorological IKS found were arranged into five categories based on their unique characteristics. The categories are vegetation, animals, birds, insects and cosmology. The findings presented below were corroborated in the interviews and focus group discussions conducted. The meteorological IKS mentioned but not substantiated in the interviews and focus group discussions, were not included in this paper.

\subsection{Rainfall Predication IKS in Chimanimani District}

\section{Vegetation}

Two meteorological IKS aspects which emerged under this category were abundance of wild fruits and flowering of certain wild flowers. Abundance of wild fruits like shuma (Baboo Gobindram), mhori and tsvedzenga indicate a good or normal rainfall season. However, it was reported that abundance of mazhanje (Uapaca kirkiana) means that rainfall will be below normal in the season concerned or even drought altogether in the year concerned. On the flowering of the indigenous trees, it was revealed that if trees like Musasa (Brachystegia spiciformis), Muswati (Dalbergiella nyasae), Muhunya (Acacia karroo Hayne), Mukamba (Afzelia quanzensis Welw) and Muchirara (Pterocarpus rotundifolius) bloom, it means the rains will fall within a week to four weeks. In addition, it was mentioned that the rains would normally be adequate to support a normal farming season.

\section{Animals}

It was pointed out that if mbira (Procavia capensis) cries, it means the rains are less than a week to fall.

\section{Birds}

It was mentioned that crying of certain birds signifies the likelihood of rainfall. For instance, if birds like Kowero and Shezhu cry, it denotes that the rains are less than a week away.

\section{Insects}

It emerged that if yellow butterflies are seen in the area, it signals normal to above normal rainfall in the season concerned.

\section{Cosmology}

The study findings also revealed that there are certain ways the people in the Chimanimani District communities study the atmosphere and make a deduction to foretell the likelihood and intensity of rainfall. Three dimensions featured under this category namely moon, sun and wind direction. About the moon, they said that if there is a big dark cloud surrounding the moon, it means that heavy rains are coming within a few days to a week. As for the sun, it was reported that if a big dark circle surrounds it, this denotes that heavy rains with strong winds are expected in the season and may be of destructive nature. It was also gathered that if wind blows from East to West, this is a good sign that it will rain but the characteristic of the rain is not always obvious. The rains may be 
normal, below or above farming requirements but certain that it will rain within hours or days.

\subsection{Prevalence Use of IKS for Prediction of Rainfall in Chimanimani District}

The data gathered and analysed revealed that the use of IKS in the communities enumerated to predict likelihood of rainfall and its characteristics has gradually been reducing in the passage of time and generations. In fact, of the 19 people in the three communities aged between 30 and 60 who were randomly asked the question about if they knew any indigenous knowledge on rainfall prediction, only three (15.7\%) mentioned one or two with limited detail and accuracy. The rest (84.3\%) just mentioned that their parents and grandparents have or had the knowledge. Two of them said, "this was used before people were educated" (YA06) while another disapproved the meteorological IKS with the argument that "they are not reliable" (YA11). The platforms mentioned where the meteorological IKS is remotely shared and discussed are community gatherings like at community beer halls, marriage ceremonies and weddings. The findings also revealed that meteorological IKS are rarely part of discussions in official community meetings such as civil protection meetings, school meetings and village development committee meetings.

\subsection{Potential Contribution of Meteorological IKS to Community Disaster Preparedness}

It was discovered that the meteorological IKS presented in this paper are not currently included in the community disaster preparedness efforts. A review of the national disaster and risk management plan also revealed that meteorological IKS were not considered (Mukanganise, 2011). If the meteorological IKS were included and given recognition, in the absence of a scientific warning system from the convention meteorological systems, they would have saved a lot of lives in the Chimanimani disaster. Communities have their way of raising alarm and taking precautions but in this case complacency was driven by overreliance on the conventional systems.

\section{Discussion}

The findings presented indicate that the meteorological IKS in the Chimanimani communities studied are varied and complementary in the prediction of rainfall patterns. It is also clear that the meteorological IKS in the communities enumerated are not publicly shared and this is one of the reasons why there is a general loss of it through generations. As pointed out by two of the study participants (AY06 and AY11) in Section 5.2, it appears that some people think that IKS is an inferior form of knowledge. When AY06 said that IKS “... was used before people were educated" suggests that Western knowledge and ontology brought through Western education system are superior and universal. It can be seen that since meteorological IKS are not included in the meteorology studies in the 
country, this could be a contributing factor of its inferioritisation, limited documentation and lack of model designs for community sustainable development.

It is also observed from the findings that the meteorological IKS are intricately dependent on the atmospheric and environmental elements. On this aspect, it can be inferred that if the indigenous trees, shrubs, birds and insects that are linked to the meteorological IKS are not properly conserved, it is likely that the community knowledge may get extinct. Since the communities enumerated are rural and some people do not have radios, television sets to receive information from meteorology department, meteorological IKS discussed in this paper could be quite a useful alternative for the residents' prediction of rainfall. Even those who may have radios or television sets, they also likely to benefit from the meteorological IKS because of the often experienced intermittent supply of electricity.

\section{Conclusion and Policy Implications}

From the foregoing discussions, it can be concluded that plurality of knowledge could provide communities with more options for meteorological information. Such a scenario will not only help the aspect of people's livelihoods but also disaster preparedness at both national and district levels of civil protection. This paper has demonstrated an emerging realist-ontological discourse in the scholarship of meteorological indigenous knowledge systems in specific rural communities. Admittedly, the meteorological IKS presented may need further research towards establishment of standardised prediction models. Also, more species of trees, birds and insects could be studied to formulate alternatives in case the traditionally known ones get extinct. It also means that sustained efforts for the conservation of the atmosphere and the environment in the communities are not an option but a necessity to preserve the rich IKS knowledge.

\section{Acknowledgements}

Great appreciation goes to Indigenous Knowledge Research Institute for Africa (IKRIA) for undertaking the meteorological IKS research in Chimanimani District in October 2019.

\section{Conflicts of Interest}

The authors declare no conflicts of interest regarding the publication of this paper.

\section{References}

Aniah, P., Aasoglenang, T. A., \& Bonye, Z. S. (2014). Behind the Myth: Indigenous Knowledge and Belief Systems in Natural Resource Conservation in North East Ghana. International Journal of Environmental Protection and Policy, 2, 104. https://doi.org/10.11648/j.ijepp.20140203.11

Battiste, M. (2005). Indigenous Knowledge: Foundations for First Nations. Worm Indigenous Nations Higher Education Consortium Journal, 1-12.

Birt, L., Scott, S., Cavers, D., Campbell, C., \& Walter, F. (2016). Member Checking: A 
Tool to Enhance Trustworthiness or Merely a Nod to Validation? Qualitative Health Research, 26, 1802-1811. https://doi.org/10.1177/1049732316654870

Boeren, E. (2019). Understanding Sustainable Development Goal (SDG) 4 on "Quality Education" from Micro, Meso and Macro Perspectives. International Review of Education, 65, 277-294. https://doi.org/10.1007/s11159-019-09772-7

Creswell, J. W. (2014). Research Design: Qualitative, Quantitative, and Mixed Methods Approaches (4th ed.). Thousand Oaks, CA: SAGE.

Fonda, M. (2011). Introductory Essay: Traditional Knowledge, Spirituality and Lands. The International Indigenous Policy Journal, 2, Article 1. https://doi.org/10.18584/iipj.2011.2.4.1

Guzzini, S. (2017). Realist Theories and Practice. København: Danish Institute for International Studies.

Harper, M., \& Cole, P. (2012). Member Checking: Can Benefits Be Gained Similar to Group Therapy? Qualitative Report, 17, 1-8.

Kaya, H. O., \& Seleti, Y. N. (2013). African Indigenous Knowledge Systems and Relevance of Higher Education in South Africa. The International Education Journal: Comparative Perspectives, 12, 30-44.

Liang, S. (2017). Incorporating Indigenous Knowledge in the Local Government's Early Warning System: A Case Study from Baringo County, Kenya. Lund: Lund University. http://lup.lub.lu.se/luur/download?func=downloadFile\&recordOId=8922488\&fileOId $=$ $\underline{8923513}$

Logan, C. (2008). Traditional Leaders in Modern Africa: Can Democracy and the Chief Co-Exist? Cape Town.

Mahony, M., \& Caglioti, A. (2017). Relocating Meteorology. History of Meteorology, 8, 1-14. https://doi.org/10.1155/2017/3913817

Makwara, C. E. (2013). Indigenous Knowledge Systems and Modern Weather Forecasting: Exploring the Linkages. Journal of Agriculture and Sustainability, 2, 98-141.

Mapara, J. (2009). Indigenous Knowledge Systems in Zimbabwe: Juxtaposing Post Colonial Theory. The Journal of Pan African Studies, 3, 139-155.

Matos-Ala, J. (2018). Making the Invisible, Visible: Challenging the Knowledge Structures Inherent in International Relations Theory in Order to Create Knowledge Plural Curricula. Johannesburg: University of Witwatersrand, Department of International Relations. https://doi.org/10.1590/0034-7329201700122

Moyo, B. H. Z. (2010). The Use and Role of Indigenous Knowledge in Small-Scale Agricultural Systems in Africa: The Case of Farmers in Northern Malawi. Glasgow: University of Glasgow.

Muchena, N. O. (1990). An Analysis of the Indigenous Knowledge Systems: Implications for Agricultural Extension Education with Particular Reference to Natural Resource Management in Zimbabwe. Ames, IA: Iowa State University.

Mukanganise, R. (2011). Disaster Preparedness at Community Level in Zimbabwe: The Case of Chirumanzu and Mbire. PhD Thesis, Harare: Women's University in Africa.

Muyambo, T., \& Maposa, R. S. (2014). Linking Culture and Water Technology in Zimbabwe: Reflections on Ndau Experiences and Implications for Climate Change. Journal of African Studies and Development, 6, 22-28. https://doi.org/10.5897/JASD2013.0266

Ndlovu-Gatshen, S. J. (2015). Decoloniality in Africa: A Continuing Search for a New World Order. Australasian Review of African Studies, 36, 22-50.

Prussin, L. (2007). An Introduction to Indigenous African Architecture. The Journal of 
the Society of Architectural Historians, 33, 182-205. https://doi.org/10.2307/988854

Ragab, M. A., \& Arisha, A. (2017). Research Methodology in Business: A Starter's Guide. Management and Organizational Studies, 5, 1. https://doi.org/10.5430/mos.v5n1p1

Riffel, A. D. (2015). An Insight into a School's Readiness to Implement a CAPS Related Indigenous Knowledge Curriculum for Meteorological Sciences. Universal Journal of Educational Research, 3, 906-916. https://doi.org/10.13189/ujer.2015.031117

Rim-Rukeh, R., Irerhievwie, G., \& Agbozu, I. E. (2015). Traditional Beliefs and Conservation of Natural Resources: Evidences from Selected Communities in Delta State Nigeria. International Journal of Biodiversity and Conservation, 41, 7-12.

Rosch, F., \& Lebow, R. N. (2018). A Contemporary Perspective on Realism. In International Relations Theory-An E-IR Foundations Beginner's Textbook (pp. 138-144). London: Cambridge.

Shava, G. N., \& Heystek, J. (2019). Agency and Structure: Principals' Ability to Bring about Sustainable Improvement in Underperforming Schools in South Africa. Africa Education Review, 16, 50-68. https://doi.org/10.1080/18146627.2017.1340809

Shizha, E. (2013). Reclaiming Our Indigenous Voices. The Problem with Postcolonial Sub-Sahara School Curriculum. Journal of Indigenous Social Development, 6, 1-18.

Sithole, P. M. (2020). Indigenous Knowledge Systems in Crop Management and Grain Storage in Chimanimani District of Zimbabwe. Southern African Journal of Environmental Education, 36, 21-32. https://doi.org/10.4314/sajee.v36i1.3

Stefanelli, R. D., Castleden, H., Harper, S. L., Martin, D., Cunsolo, A., \& Hart, C. (2017). Experiences with Integrative Indigenous and Western Knowledge in Water Research and Management: A Systematic Realist Review of Literature from Canada, Australia, New Zealand, and the United States. Environmental Reviews, 25, 323-333.

https://doi.org/10.1139/er-2016-0114 